\title{
Solar Cooker Study under Oman Conditions for Late Evening Cooking Using Stearic Acid and Acetanilide as PCM Materials
}

\author{
Nagaraj Nayak, Hatim Abu Jarir, and Haitham Al Ghassani \\ Caledonian College of Engineering, Seeb, Oman \\ Correspondence should be addressed to Nagaraj Nayak; nagarajsnayak@gmail.com
}

Received 26 July 2016; Accepted 13 October 2016

Academic Editor: Koray Ulgen

Copyright (C) 2016 Nagaraj Nayak et al. This is an open access article distributed under the Creative Commons Attribution License, which permits unrestricted use, distribution, and reproduction in any medium, provided the original work is properly cited.

\begin{abstract}
Solar energy is an alternative source of nonrenewable energy in Oman. Sultanate of Oman government showed initiation into utilization of solar energy for domestic applications. Conversion of solar radiation into useful heat is the simplest application of solar energy, in which it can be used for late evening cooking. In this context, present work highlighted the design and development of solar cooker for Oman climatic conditions. The current work signifies usage of solar cooker for late evening cooking using stearic acid and acetanilide as phase change materials (PCM). Solar cooker parts are developed in-house and connected to water heating system compounded with evacuated tubes solar collector and storage tank. The circumference of cooker unit is incorporated with spiral stainless steel heat exchanger and annulus area of the pot is filled with PCM material. PCM releases heat at late evening and effective cooking up to 7:30 PM is noticed. The experimental results indicated the cooker efficiency of $30 \%$ and collector efficiency of $60-65 \%$ during the study. Overall, experiments showed satisfactory performance on the developed cooker.
\end{abstract}

\section{Introduction}

According to statistics, $50 \%$ of the commercial sources of energy like petrol, gas, and electricity are used in our daily consumption. Humans should take advantage of other sources of energy; renewable energy is one of the alternative available energy sources. It is also essential to encourage the community to start using alternative energy sources for the sake of cleaner environment. Solar cooker is now an invention that uses solar energy for late evening cooking.

In the late 1950s, the scientist Maria Telkes was the person who worked on box type solar cooker. Later, the mid of the 20th century showed a number of individuals and groups experimenting projects on solar cookers. The technical concept of solar cooker can be evaluated by thermal storage potential and energy is stored by raising the temperature of a storage medium; therefore, phase change materials (PCM) play important role in the present scenario. These materials have the ability to store large amounts of thermal energy under isothermal conditions, which means they can deliver or store energy at constant temperature and excrete the heat whenever there is a difference in the degree of the temperature.
Sharma et al. [1] investigated the thermal performance of solar cookers based on an evacuated tube solar collector with PCM storage unit. The experiment results indicated that the noon cooking did not affect the evening cooking and that evening cooking using PCM heat storage unit is faster than noon cooking. Similarly, Agrawal and Yadav [2] carried out experiments with solar cooker with two sensible heat storage materials for evening cooking. They used a parabolic type of solar cooker and sensible heat storage materials like iron grits and iron balls. In their study relationship between the temperature and the solar radiation intensity for both sensible heat materials is noticed; experimental results highlighted the fact that solar cooker is more efficient when filling the iron balls in the inner space and the iron grits in the outer space. In addition, Sharma et al. [3] designed, developed, and performed evaluation of the latent heat storage unit for evening cooking of solar cooker. Cooking experiments are conducted with different loads and loading times during the summer and winter seasons. The experimental results showed that evening cooking is possible with a solar cooker having the PCM storage unit and is not possible in a standard solar cooker. Kassem [4] carried out experiment on box type solar cooker with heat storage unit. The experiment 


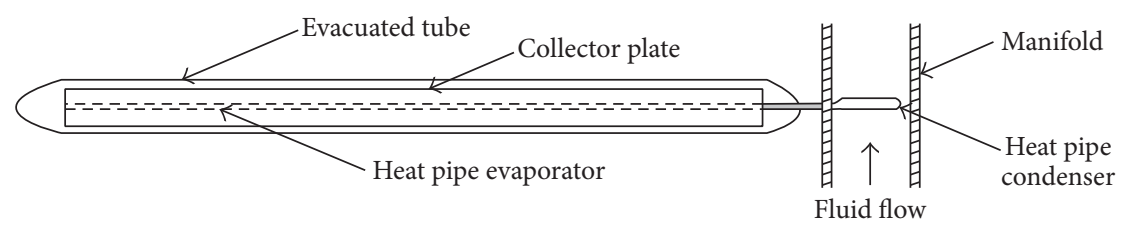

FIGURE 1: Schematic diagram of evacuated tube collector [6].

setup included solar water heating that contained evacuated tubes solar collectors and storage unit. Paraffin was used as the phase change material in heat storage unit. He found that solar cooker based on evacuated tubes solar collector with PCM unit gave good performance in the conditions of high elevation. In a similar way, Saini et al. [5] studied the concept of solar cooker and designed a solar cooker for late cooking. Their study demonstrated different designs for solar cooker and studied the performance of solar collector. The study results revealed that solar cookers are helpful in minimizing $\mathrm{CO}_{2}$ emissions and the cylindrical storage unit is preferred over rectangular storage unit. In addition, solar cookers having PCM which melts above $100^{\circ} \mathrm{C}$ are more promising for the storage unit of the solar cooker.

With this thought, present work signifies the design, development, and comparison of the performance of the solar cooker using stearic acid and acetanilide as phase change materials for Oman conditions. Thermal calculations are made for evacuated tube collector, PCM storage system, and studying the performance at different loadings.

\section{Analysis of Solar Cooker System}

2.1. Intensity of Solar Radiation. The placement of earth's orbit around the sun is such that sun-earth distance varies by 1.7 percent and solar radiation outside the earth's atmosphere is nearly of fixed intensity; the radiant energy flux received per second by a surface of unit area held normal to the direction of sun's rays at the mean earth-sun distance is constant throughout the year. This is called as solar constant, $I_{\mathrm{SC}}$, and its value is $1367 \mathrm{~W} / \mathrm{m}^{2}$. However, this space radiation suffers variation due to the fact that earth rotates around the sun not in a circuital orbit but follows an elliptic path. The intensity of extraterrestrial radiation $I_{\text {ext }}$ measured on a plane normal to the radiation on $n$th day of the year is given in terms of solar constant $\left(I_{\text {sc }}\right)[7]$ :

$$
I_{\text {ext }}=I_{\text {sc }}\left[1+0.033 \cos \left(\frac{360 n}{365}\right)\right] \text {. }
$$

In addition, on the basis of transmission coefficients, latitude, declination, and hour angle, the total heat received on horizontal surface at ground is calculated from the relation

$$
\begin{aligned}
I_{\text {total }}= & I_{\text {ext }}\left(\tau_{b}+\tau_{d}\right) \\
& \cdot(\cos \varphi * \cos \delta * \cos \omega+\sin \varphi * \sin \delta),
\end{aligned}
$$

where $\tau$ is transmission coefficient, $\varphi$ is latitude angle, $\delta$ is declination, and $\omega$ is hour angle.
2.2. Evacuated Tube Collector with Heat Pipe. Normally, evacuated tube collector with heat pipe consists of a metal fin and is used for maximum heat transfer from absorbed solar energy at the absorber. The evaporator is exposed to solar radiation and condenser is attached with tube in configuration plate. The working fluid flows through tube flat plate of condenser.

A schematic view of an evacuated tube collector with heat pipe and the condenser is shown in Figure 1. The condenser of heat pipe transfers the heat to the fluid through a manifold. Each fin plate with heat pipe absorber is enclosed in a separate evacuated cylindrical tube.

Under steady condition, the rate of useful energy available with evacuated tube solar collector can be represented by the equation

$$
Q_{u}=A_{c}\left[q_{\mathrm{ab}}-U_{L}\left(T_{p}-T_{a}\right)\right]
$$

where $q_{\mathrm{ab}}$ is absorbed solar radiation in $\mathrm{W} / \mathrm{m}^{2} ; U_{L}$ is overall heat loss coefficient in $\mathrm{W} / \mathrm{m}^{2} \mathrm{~K} ; T_{a}$ is ambient temperature in $\mathrm{K}$; and $A_{c}$ is surface area of collector in $\mathrm{m}^{2}$.

The thermal efficiency of collector is calculated from

$$
\eta=\frac{Q_{u}}{I A_{c}}
$$

2.3. Phase Change Materials. Phase change materials are latent heat storage materials and energy release occurs when a material changes its phase from solid to liquid or vice versa. In general, they absorb and release heat at constant temperature and can store more heat per unit volume than sensible heat storage materials. Fatty acids have high heat of fusion values comparable to that of paraffin's and their major drawback is 2-2.5 times costlier than paraffin's. In the current work stearic acid and acetanilide is used as PCM.

Characteristics of Phase Change Materials. Stearic acid is a saturated fatty acid with an 18-carbon chain. It is a waxy solid and chemical formula is $\mathrm{C}_{17} \mathrm{H}_{35} \mathrm{CO}_{2} \mathrm{H}$. Stearic acid can store the thermal energy and chemical phase will change from solid to liquid and from liquid to solid during thermal process.

Similarly, acetanilide is a solid chemical used to store the thermal heat energy in the form of latent heat. It is also known as $\mathrm{N}$-phenylacetamide, acetanil, and acetanilide. Table 1 highlights the thermophysical properties of phase change materials and Figure 2 indicates enthalpy curves of phase change materials.

\section{Results and Discussion}

3.1. Solar Intensity of Radiation. Before starting the experiment, solar intensity calculation has been carried out to 


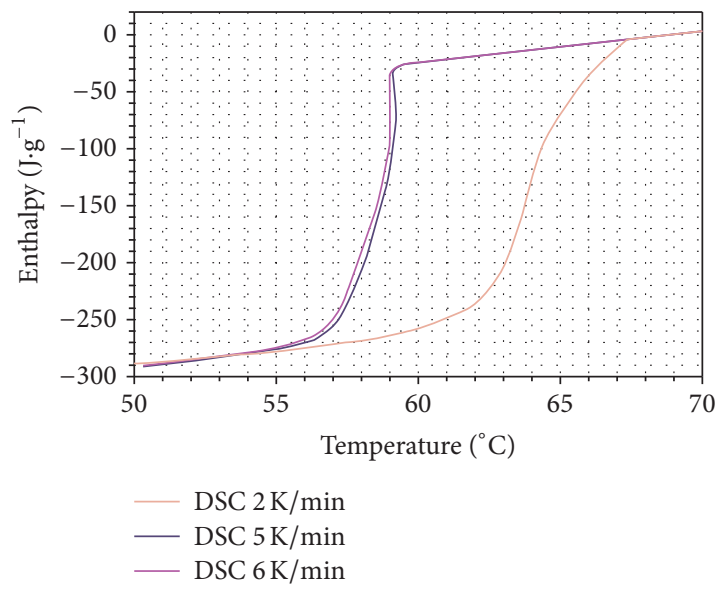

(a) Stearic acid [8]

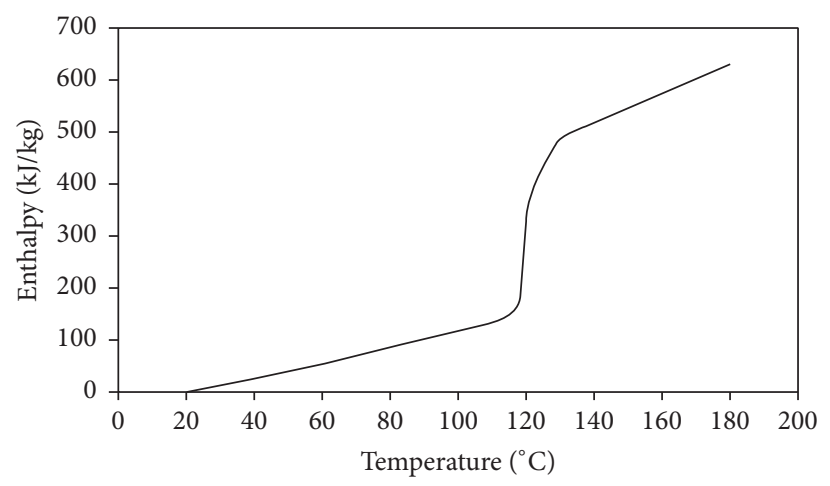

(b) Acetanilide [9]

FIGURE 2: Enthalpy curves of phase change materials. Orange, blue, and purple lines in Figure 2(a) represent DSC data for $2 \mathrm{~K} / \mathrm{min}, 5 \mathrm{~K} / \mathrm{min}$, and $6 \mathrm{~K} / \mathrm{min}$, respectively.

TABLE 1: Thermophysical properties of the phase change materials.

\begin{tabular}{lcc}
\hline Name & Stearic acid & Acetanilide \\
\hline Chemical structure & $\mathrm{C}_{17} \mathrm{H}_{35} \mathrm{CO}_{2} \mathrm{H}$ & $\mathrm{C}_{8} \mathrm{H}_{9} \mathrm{NO}$ \\
Molecular weight, g/mol & 284.4772 & 135.17 \\
Melting point, ${ }^{\circ} \mathrm{C}$ & 69.5 & $114-116$ \\
Heat of fusion, J/g & 192.09 & 162.90 \\
Density, $\mathrm{kg} / \mathrm{m}^{3}$ & 847 & 1219 \\
\hline
\end{tabular}

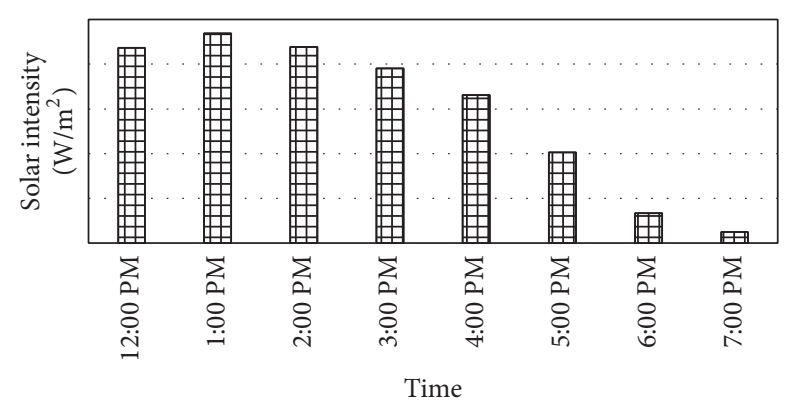

Figure 3: Solar intensity data (dated: May 9, 2016).

determine intensity of solar radiation in Oman. The study highlighted that the solar intensity in the summer period is nearer to $1000 \mathrm{~W} / \mathrm{m}^{2}$ in Oman. Pyranometer unit is used to record the solar intensity in the month of May 2016. During the experiment, a maximum solar intensity value of $938 \mathrm{~W} / \mathrm{m}^{2}$ is noted on May 9,2016 , at $2 \mathrm{PM}$, and in the late evening, the value reduced to $49 \mathrm{~W} / \mathrm{m}^{2}$ at $7 \mathrm{PM}$; see Figure 3 . The study gave the confidence in the calculation of solar intensity of radiation in Oman.

3.2. Thermal Analysis on Evacuated Tube Solar Collector. Similarly, from theoretical relations, the parameters like useful energy, final temperature of water, and efficiency of
TABLE 2: Thermal analysis results for evacuated tube solar collector.

\begin{tabular}{lc}
\hline Parameter & Values \\
\hline Useful energy, W & 90.474 \\
Final temperature of water, ${ }^{\circ} \mathrm{C}$ & 134.4 \\
Efficiency of evacuated tube solar collector, \% & 63.4 \\
\hline
\end{tabular}

TABLE 3: Specification of evacuated tube solar collector.

\begin{tabular}{lc}
\hline Item & Specification \\
\hline Number of collector tubes & 10 tubes \\
Outer diameter of the collector tube & $58 \mathrm{~mm}$ \\
Tube length & $500 \mathrm{~mm}$ \\
Total area of evacuated tube & $84 \mathrm{~cm} \times 58 \mathrm{~cm}, 58 \mathrm{~cm}$ height \\
\hline
\end{tabular}

evacuated tube solar collector are calculated. Refer to Table 2 for the values calculated from thermal analysis.

\subsection{Experimental Validation}

Experiment Setup. The solar cooker setup consists of an evacuated tube solar collector, closed-loop water line, PCM storage unit, stainless steel heat exchanger, and cooking vessel. The specifications of the evacuated tube solar collector are highlighted in Table 3.

Figure 4 indicates the assembly of evacuated tube solar water heater used for the solar cooker.

In the present work, a storage unit is provided with two hollow concentric aluminum cylinders; its inner and outer diameters are $250 \mathrm{~mm}$ and $350 \mathrm{~mm}$, respectively, and $300 \mathrm{~mm}$ deep. The space between the inner diameter and outer diameter is filled with PCM materials; see Figure 5(a). Two separate storage units' setup is made to study the performance with acetanilide and stearic acid as PCM materials. From thermal analysis calculations, it is confirmed that $2.5 \mathrm{~kg}$ stearic acid and $3 \mathrm{~kg}$ acetanilide will be sufficient to achieve 


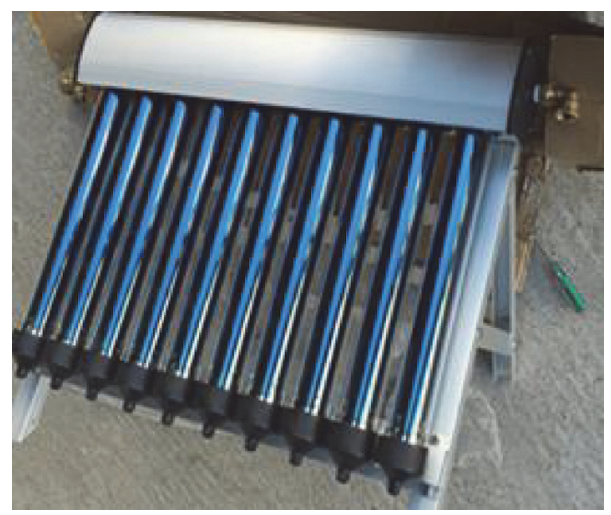

FIGURE 4: Assembly of evacuated tube solar water heater.

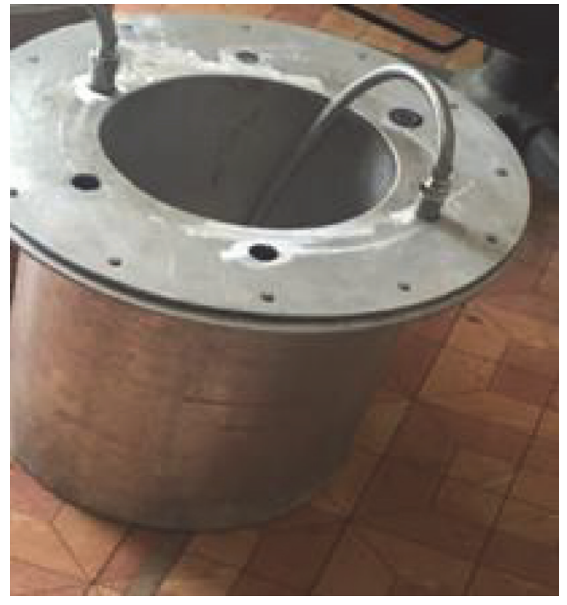

(a) PCM storage unit

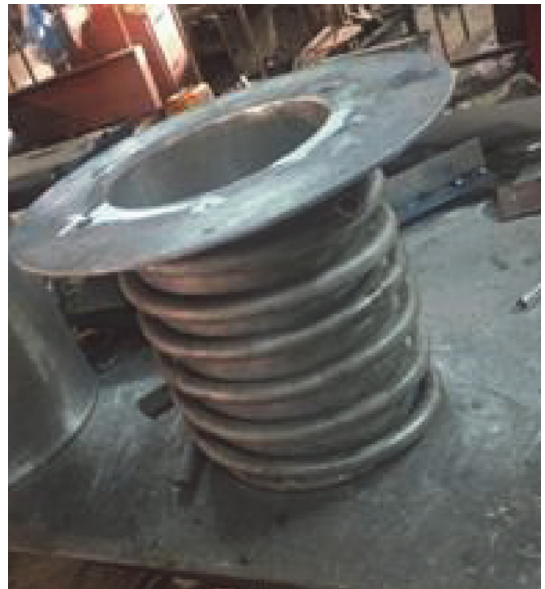

(b) Stainless steel heat exchanger

FIGURE 5: In-house developed parts of solar cooker.

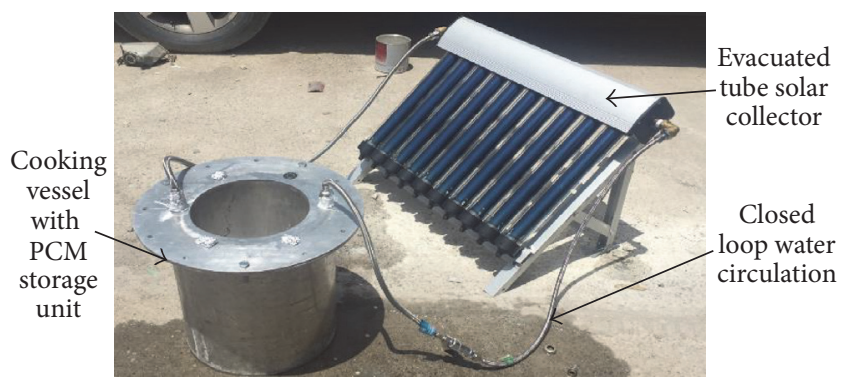

Figure 6: Complete setup of solar cooker.

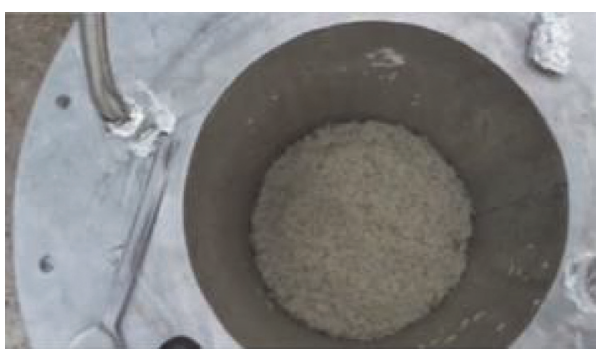

FIGURE 7: The late evening cooking of rice. the required $\mathrm{PCM}$ temperature of $125^{\circ} \mathrm{C}$ for late evening cooking. Thermocouples are mounted at different locations of storage unit and water flow path to measure the PCM and water temperatures. A stainless steel piping is used for heat exchanging water with PCM that wraps around the cooking (Figure 5(b)). Figure 6 reveals the complete setup used for cooking experiments.

Experiment Methodology. Experimental study on solar cooker is performed in the month of May 2016. During sunshine hours, the heated water transfers heat to the PCM and the heat is stored in the form of latent heat. This stored heat is utilized to cook the food in the evening when the sun intensity is not sufficient to cook food. See Figure 7 for cooking of the rice in the late evening. In the current study, acetanilide and stearic acid are used as phase change materials. The PCM storage unit and piping system are insulated to prevent the heat losses. A valve between the evacuated tube solar collector and storage unit controls the water flow.

In addition, other parameters like water outlet and PCM storage temperatures are recorded at regular intervals. In 


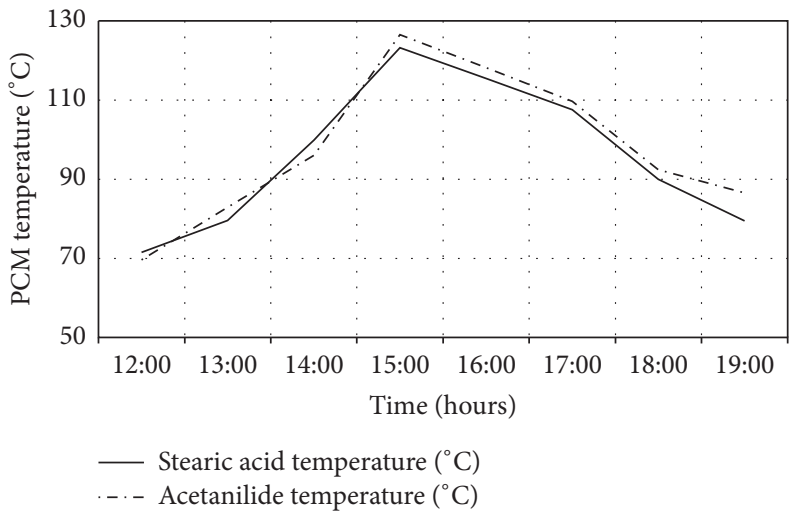

(a) $1 \mathrm{~kg}$ water in the vessel

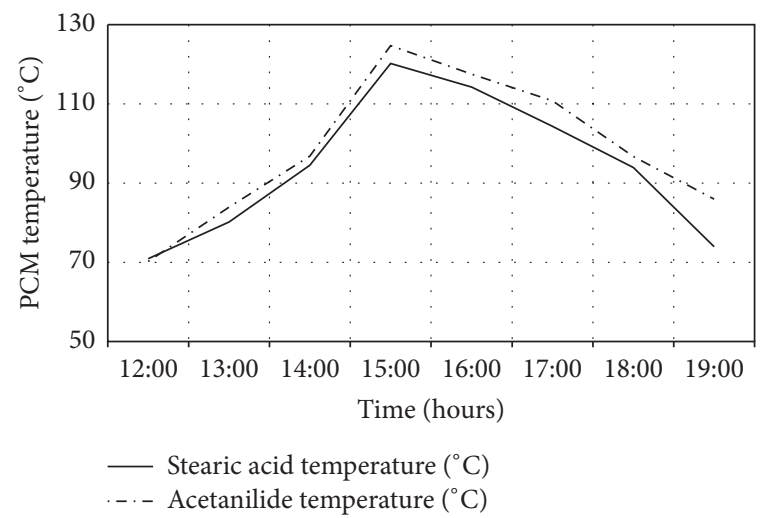

(b) $2 \mathrm{~kg}$ water in the vessel

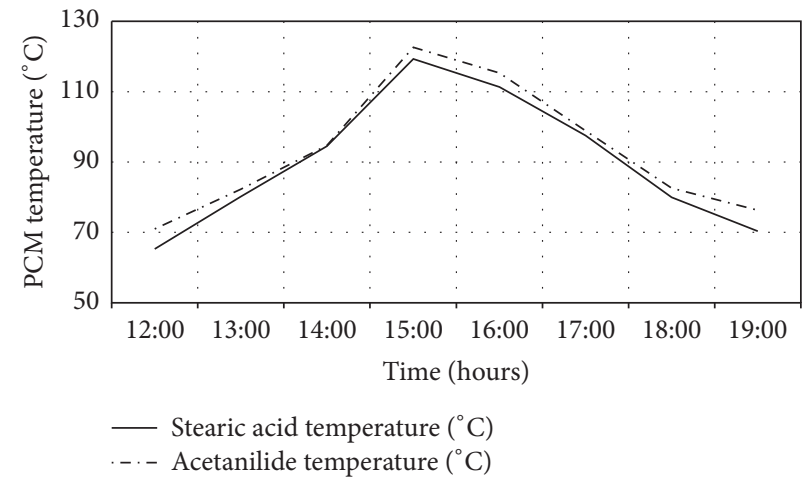

(c) $3 \mathrm{~kg}$ water in the vessel

Figure 8: Variation of PCM temperature at different loadings in the vessel.

addition, solar cooker is studied for different loadings of water in the vessel. Figure 8 explains the variation of PCM temperature at different loadings in the vessel. This reading corresponds to thermometer mounted at centerline (right side) of annulus area of PCM. From the experimental study it is confirmed that acetanilide temperature is higher than the stearic acid. Also, in late evening, that is, at $7 \mathrm{PM}$, for all loadings acetanilide showed the temperature of $78-88^{\circ} \mathrm{C}$. This temperature enables cooking the food items effectively in late evening. In a similar way, water outlet temperature is recorded during the testing; see Figure 9 and it is observed that maximum water outlet temperature of $130^{\circ} \mathrm{C}$ at $3 \mathrm{PM}$ on May 9, 2016, is noticed. It is due to higher solar intensity on that day.

From the test results, it is observed that, until $3 \mathrm{PM}$, the temperature of PCM material is lower than water outlet temperature. However, in late evening, water temperature drops substantially as compared to PCM temperature. It is due to the fact that heat content of PCM is high, so fewer drops are noticed in the evening and this helped to cook the rice effectively.

Heat Storage in PCM and Collector Performance. The measured experiment data is used to evaluate the parameters like energy storage capacity of PCM material and water. The total heat stored in the PCM is calculated by analyzing the enthalpy inside PCM storage unit from the measured PCM temperatures. Similarly, total heat gain by water is evaluated

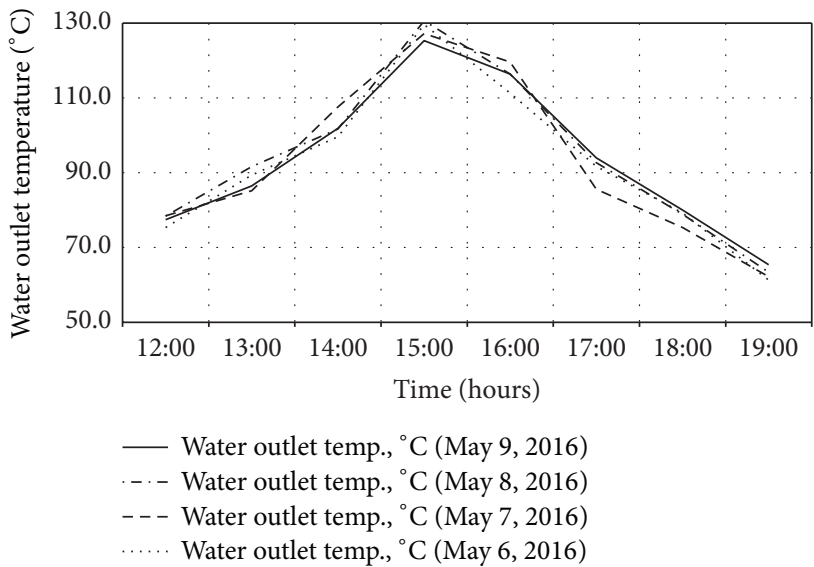

FIGURE 9: Variation of water outlet temperature.

from measured outlet water temperatures. From the study, it is confirmed that cooker performance is directly related to energy storage capacity of PCM and solar intensity of radiation. In addition, collector performance is evaluated from heat energy gained by water from solar radiation. Experimental results of energy content of PCM and heat gain by water are tabulated in Table 4 . From the study, it is confirmed that cooker showed better performance for all the loadings with acetanilide compared to the stearic acid. A 60 $65 \%$ collector efficiency is noticed from experiment results 
TABLE 4: Observed values of heat gained by water and heat stored by PCM.

\begin{tabular}{|c|c|c|c|c|c|c|c|c|c|c|}
\hline \multirow{2}{*}{ Date } & \multirow{2}{*}{ Load, kg } & \multirow{2}{*}{$\begin{array}{c}\text { Max. solar } \\
\text { intensity } \mathrm{W} / \mathrm{m}^{2}\end{array}$} & \multicolumn{4}{|c|}{ Acetanilide } & \multicolumn{4}{|c|}{ Stearic acid } \\
\hline & & & $Q_{\mathrm{PCM}}, \mathrm{MJ}$ & $Q_{\text {water }}, M J$ & $\eta_{\text {collector }}, \%$ & $\eta_{\text {cooker }}, \%$ & $Q_{\mathrm{PCM}}, \mathrm{MJ}$ & $Q_{\text {water }}, M J$ & $\eta_{\text {collector }}, \%$ & $\eta_{\text {cooker }}, \%$ \\
\hline${ }^{*}$ May 6 & 1 & 900 & 1.99 & 4.03 & 63 & 31 & - & - & - & - \\
\hline${ }^{*}$ May 7 & 2 & 938 & 2.02 & 4.12 & 65 & 31 & - & - & - & - \\
\hline${ }^{*}$ May 8 & 3 & 890 & 1.99 & 2.66 & 63 & 31 & - & - & - & - \\
\hline${ }^{*}$ May 9 & 1 & 895 & - & - & - & - & 1.57 & 4.03 & 64 & 25 \\
\hline${ }^{*}$ May 10 & 2 & 906 & - & - & - & - & 1.60 & 4.21 & 65 & 25 \\
\hline${ }^{*}$ May 11 & 3 & 885 & - & - & - & - & 1.55 & 3.67 & 60 & 25 \\
\hline
\end{tabular}

${ }^{*}$ Data recorded in year 2016.

and is almost nearer to the value predicted from thermal analysis. In addition, a maximum cooker efficiency of $30 \%$ is noticed, and this value is very low and could be improved in the future by increasing heat storage capacity of PCM material and providing fins around copper coil and also by minimizing leakages in the system.

\section{Conclusion}

In the present study, thermal performance of a solar cooker coupled with PCM heat storage unit and evacuated tube solar collector is studied for Oman conditions. A simple cylindrical PCM heat storage unit is designed to store solar energy during sunshine hours and to cook food in the late evening. The experiment results from the present setup drives the following conclusions.

(i) The solar cooker system is able to cook successfully in evening time up to 7:30 PM by providing PCM storage unit, and PCM material temperature reached more than $120^{\circ} \mathrm{C}$ at $3 \mathrm{PM}$, which is sufficient to cook the food in the evening time.

(ii) The study results indicated that acetanilide would be better than stearic acid from the performance point of view.

(iii) During the experiment, collector efficiency of $60 \sim$ $65 \%$ and cooker efficiency of $30 \%$ are noticed with acetanilide as PCM. Overall, the present study showed satisfactory performance under Oman conditions.

\section{Competing Interests}

The authors declare that they have no competing interests.

\section{References}

[1] S. D. Sharma, T. Iwata, H. Kitano, and K. Sagara, "Thermal performance of a solar cooker based on an evacuated tube solar collector with a PCM storage unit," Solar Energy, vol. 78, no. 3, pp. 416-426, 2005.

[2] H. Agrawal and A. Yadav, "Design and experimental testing of solar cooker with sensible heat storage," Journal of Energy Research and Environmental Technology, vol. 2, no. 3, pp. 200204, 2015.
[3] S. D. Sharma, D. Buddhi, R. L. Sawhney, and A. Sharma, "Design, development and performance evaluation of a latent heat storage unit for evening cooking in a solar cooker," Energy Conversion and Management, vol. 41, no. 14, pp. 1497-1508, 2000.

[4] T. K. Kassem, "Investigation of solar cooker with PCM heat storage for high altitude places," International Journal of Mechanical Engineering \& Technology, vol. 3, no. 3, pp. 555-564, 2012.

[5] P. Saini, V. Sharma, C. Singh, and S. Singh, "Solar cooker for offsunshine cooking," Journal of Academia and Industrial Research, vol. 3, no. 9, pp. 438-444, 2015.

[6] G. N. Tiwari, Solar Energy_Fundamentals, Design, Modelling and Applications, Narosa Publications, New Delhi, India, 2002.

[7] J. A. Duffie and W. A. Beckman, Solar Engineering of Thermal Processes, John Wiley \& Sons, 4th edition, 2013.

[8] C. Rathgeber, H. Schmit, and S. Hiebler, "Mixture of alkanes, fatty acids and alcohols as novel phase change materials: preparation and characterization with DSC and T-history," in Proceedings of the 2nd International Conference on Sustainable Energy Storage, Dublin, Ireland, June 2013.

[9] M. Kenisarin and K. Mahkamov, "Solar Energy storage using phase change materials," Renewable and Sustainable Energy Reviews, vol. 11, no. 9, pp. 1913-1965, 2007. 

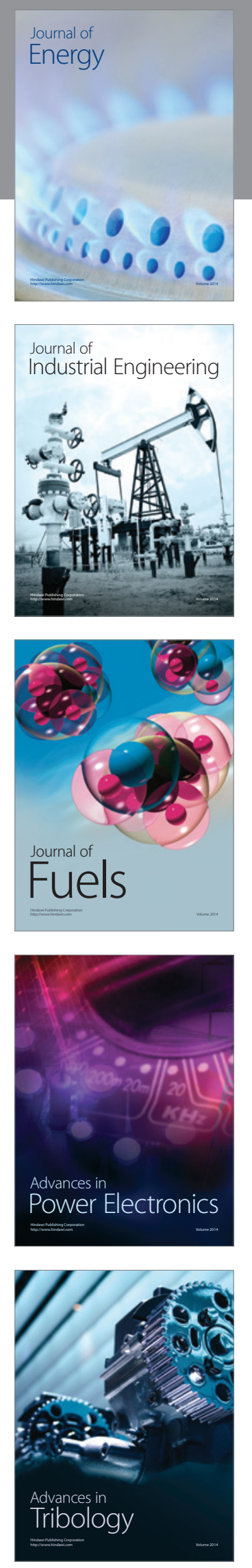
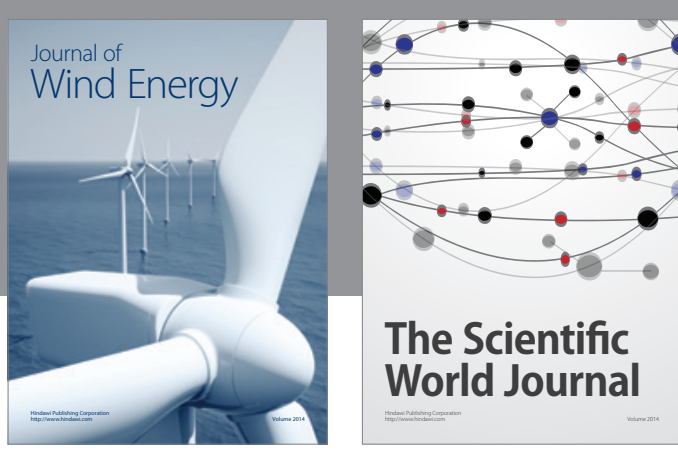

The Scientific World Journal
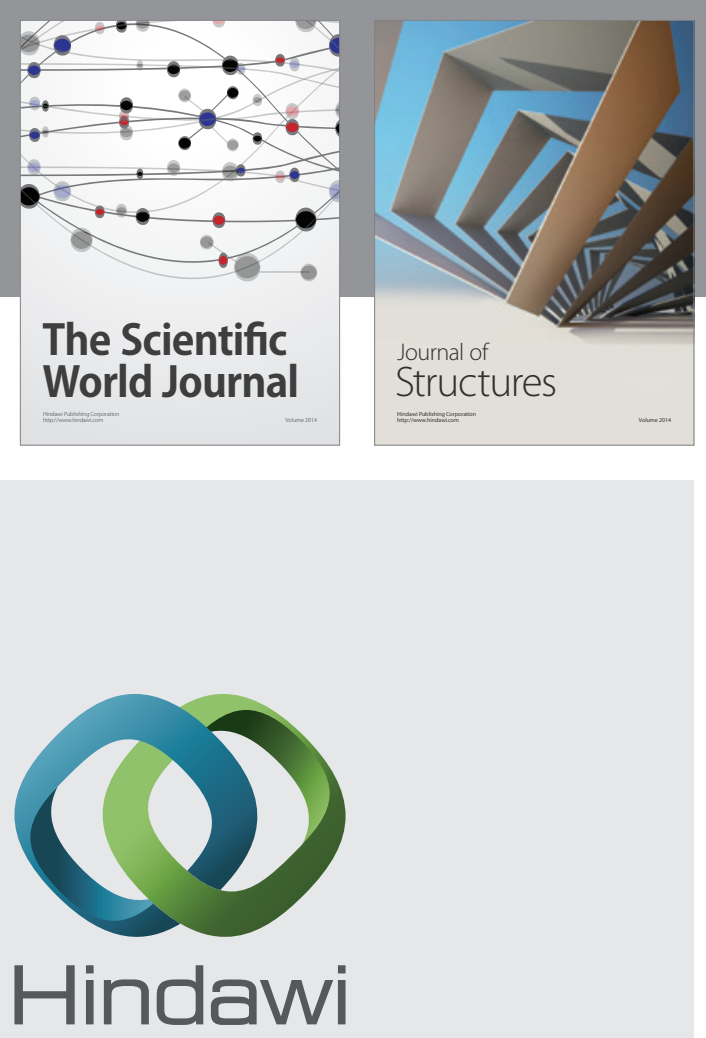

Submit your manuscripts at

http://www.hindawi.com
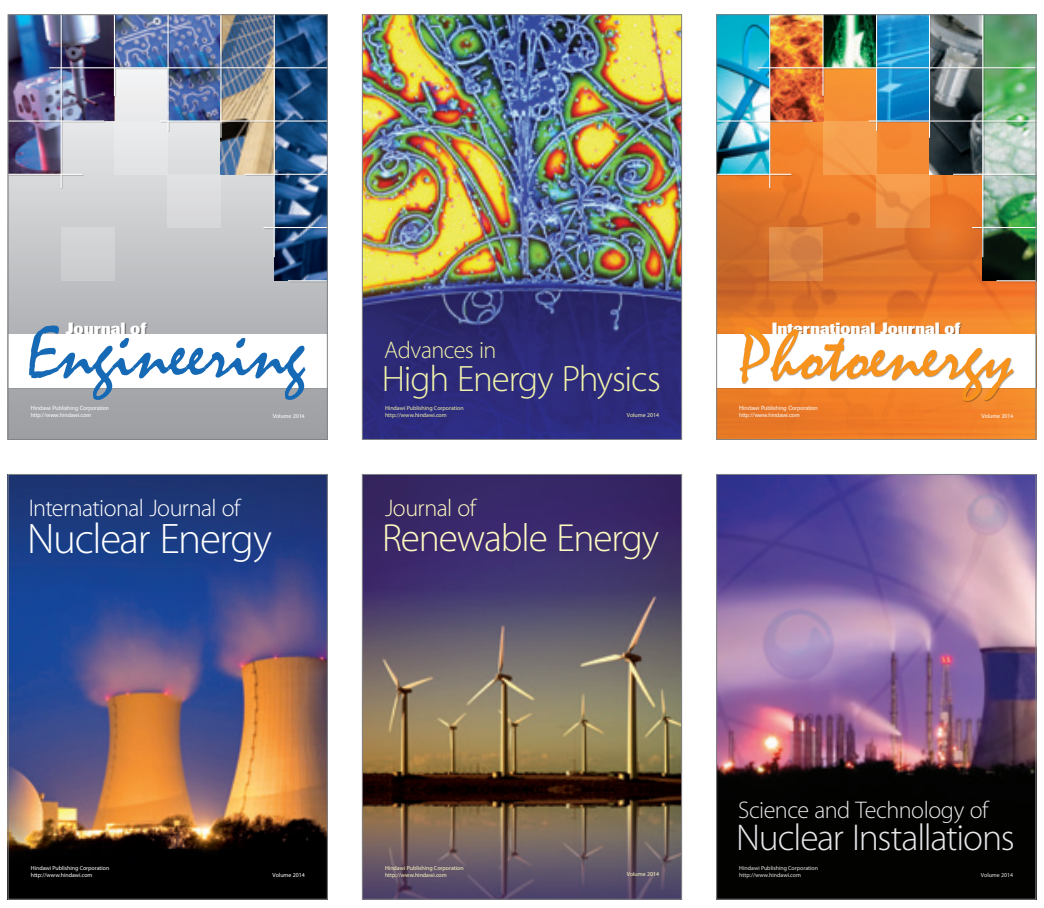
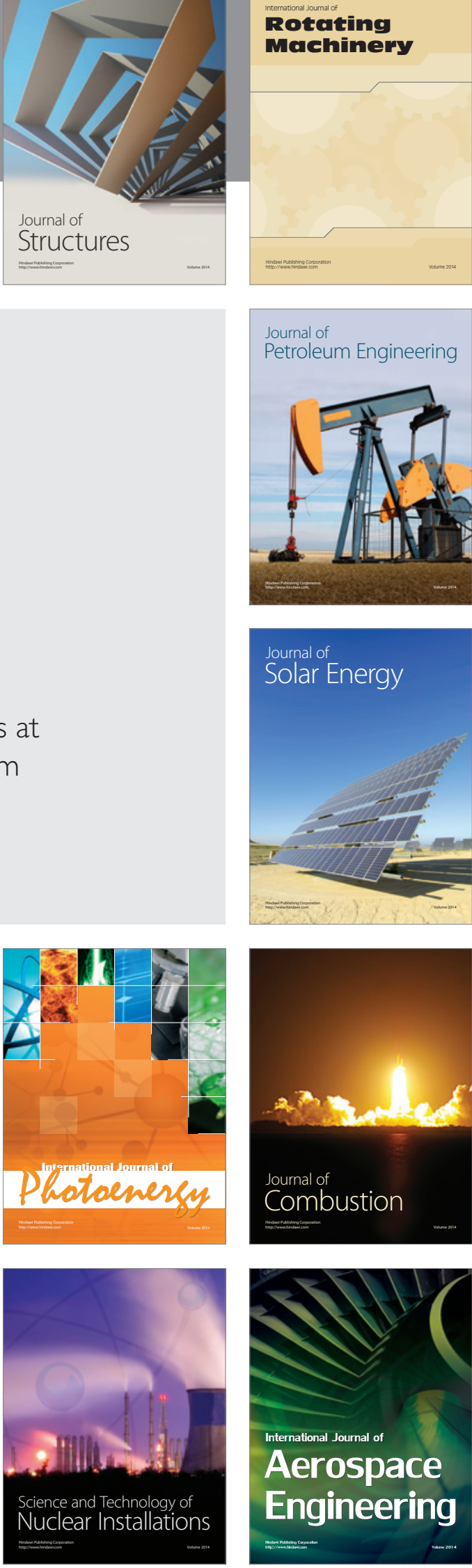